\section{ENTENDER DIREITO É UM DIREITO DE TODOS} \\ Helena Cristina Lübke \\ Professora do Centro Universitário Católica de Santa Catarina - campus Jaraguá \\ do Sul \\ Doutoranda em Estudos da Linguagem pela UEL (Universidade Estadual de Londrina \\ lena.cl@terra.com.br
}

\title{
RESUMO
}

A maneira de se expressar dos Operadores do Direito enseja uma revisão. Deve-se considerar que o Direito é uma ciência, portanto exige uma linguagem correspondente, bem como o uso de termos técnicos, formalidades e solenidades. Porém, duas grandes questões estão presentes neste trabalho: a) onde termina a arte de uma técnica escrita bem empregada e começa a perda da clareza do texto; b) em que medida a simplificação da linguagem jurídica tem efeito sobre o processo argumentativo nos textos jurídicos. O presente artigo versa sobre o excesso de formalismo/rebuscamento que torna a linguagem jurídica obscura e de difícil compreensão ao jurisdicionado. Concentra-se o estudo na busca por uma linguagem mais clara, objetiva e precisa, lembrando que cabe ao profissional do Direito ter sensibilidade e saber com que estará lidando ao exercer o seu ofício.

Palavras-chave: Juridiquês; Linguagem x Obscuridade; Simplificação; Direito.

\begin{abstract}
The way to express the Law operators gives rise to a review. One should consider that law is a science therefore requires a corresponding language, as well as the use of technical terms, formalities and ceremonies. However, two major issues are present in this paper: a) where it ends the art of a well- used technical writing and begins to loss of clarity of the text; b) the extent to which the simplification of the legal language has no effect on the argumentative process in the legal texts. This article deals with the excessive formalism that makes obscure legal language and difficult to understand the claimants. Focuses on the study in the search for clearer language, objective and accurate, noting that it is the law to have professional sensitivity and knowledge that will be dealing in exercising their craft.
\end{abstract}

Keywords: Legal term; Language x Obscurity; Simplification; Law.

\section{INTRODUÇÃO}

"Com espia no referido precedente, plenamente afincado, de modo consuetudinário, por entendimento turmário iterativo e remansoso, e com amplo supedâneo na Carta Política, nue preceitua garantia ao 


\section{SEMINÁRIO DE PESQUISA EM CIÊNCIAS HUMANAS - SEPECH \\ Humanidades, Estado e desafios didático-científicos \\ Londrina, 27 a 29 de julho de 2016}

contencioso, nem absoluta nem ilimitada, padecendo ao revés dos temperamentos constritores limados pela dicção do legislador infraconstitucional, resulta de meridiana clareza, tornando despicienda maior peroração, que o apelo a este Pretório se compadece do imperioso prequestionamento da matéria abojada na insurgência, tal entendido como expressamente abordada no Acórdão guerreado, sem o que estéril se mostrará a irresignação, inviabilizada ab ovo por carecer de pressuposto essencial ao desabrochar da operação cognitiva”. (apud MACIEL, 2007: 2).

Entendeu alguma coisa?

O texto postado em site jurídico pelo professor de Português e Literatura, Roger Luiz Maciel, traz uma ideia dos termos linguísticos rebuscados, arcaicos, misturados com verbos que ninguém conjuga e que, costumeiramente, são utilizados pela maioria dos "juristas" no Brasil.

Diante dessa complexidade linguística presente no vocabulário dos operadores de Direito, que faz existir um buraco na comunicação entre a comunidade leiga e os intelectuais juristas, discorrer-se-á sobre a importância da clareza na linguagem jurídica, com pretensão de desmistificar essa linguagem empolada, recheada de vícios, citações desnecessárias, que prolongam os prazos de execução dos processos e tornam a justiça cara e morosa.

Em matéria de direito e linguagem, é possível encontrar um ponto de equilíbrio entre o discurso técnico e a linguagem cotidiana que possa colocar o judiciário ao alcance de todos.

\section{CLAREZA NA LINGUAGEM JURÍDICA É FUNDAMENTAL}

Sabe-se que a palavra tem fundamental importância no dia a dia de todos, principalmente na vida do operador do Direito, haja vista que a ciência jurídica é a mais linguística de todas as instituições. Conforme diz Gabriel Chalita (2009: 59):

A palavra é, em si, o elemento maior da sedução, o principal recurso à disposição de advogados e promotores para exercerem suas funções. Ela é, mais do que por assim dizer, a ferramenta de trabalho do profissional do Direito.

A linguagem permite ao homem entender a evolução das relações sociais e pessoais, uma vez que lhe permite expressar seu entendimento acerca de assuntos os quais lhe interessam e são necessários. Sendo assim, essa linguagem deve ser acessível a todos.

Então, vem o questionamento: qual o papel dos operadores de direito frente à linguagem rebuscada e, por vezes, obscura da área jurídica? Logicamente, cabe ao profissional da área jurídica facilitar ao seu interlocutor, isto é, ao jurisdicionado, o entendimento frente àquilo que este busca na esfera jurídica: seus direitos. Mas sabe-se que nem sempre isso acontece, pois a linguagem jurídica possui muitos vocábulos que para boa parte da população não são compreensíveis.

Para Chalita (2007: 59): 


\section{SEMINÁRIO DE PESQUISA EM CIÊNCIAS HUMANAS - SEPECH \\ Humanidades, Estado e desafios didático-científicos \\ Londrina, 27 a 29 de julho de 2016}

Frases bem articuladas podem garantir que os significados sejam transmitidos corretamente, no que diz respeito à objetividade. A palavra é importante, sem dúvida, para comunicar fatos, idéias, pedidos ou ordens, raciocínios, em suma, um significado objetivo, que pode ser compartilhado por meio dela entre diferentes pessoas [...]

Quanto à rapidez, que caracteriza a comunicação atual, Maciel (2007) entende que a linguagem jurídica não prosperou e enfatiza:

O "modus expressandi" dos operadores de direito enseja uma revisão. A maneira como se redige um texto jurídico deve ser repensada. Não é apenas uma necessidade formal, no tocante ao uso da língua consoante à gramática ou segundo técnicas de redação; impõe-se uma necessidade de ordem prática, tendo em conta toda a sociedade juridicamente assistida. O destinatário da mensagem não é apenas o juiz, o desembargador ou o ministro, mas também o bancário, o mecânico e o comerciante...

Enfim, todos que precisam ser amparados pela justiça. Poucos conseguem entender sequer a procuração que assinam para o advogado, tanto menos será compreensível uma petição ou um recurso, também carecendo de tradução o despacho ou a sentença expedida pelo magistrado. (MACIEL, 2007: 2).

Em relação ao rigor formal, é sabido que este é necessário ao procedimento jurídico, uma vez que o ramo do direito é repleto de formalidades, solenidades, termos técnicos e lógicos. Coan (2009) afirma que o Direito é uma ciência e que, por isso, exige uma linguagem correspondente, pois detém vocabulário refinado e específico, com terminologia própria, mas, em função disso, não pode se distanciar totalmente dos sentidos originários dos verbetes encontrados no dicionário, ou seja, deve haver harmonia no sentido de similaridade representativa das ideias entre emissor/receptor.

Tal autor também salienta que:

[...] para esse trabalho persuasivo/interpretativo será exigido o nível culto da linguagem (rebuscado; ritualizado, inclusive), devendo o seu operador demonstrar capacidade para se expressar com grau de formalidade adequado ao assunto e a seu interlocutor, pois não se valerá, como cediço, do mesmo modo discursivo para tratar de temas técnicos e de temas familiares, bem como não utilizará o mesmo padrão ou registro de linguagem para se dirigir a um amigo e para se comunicar com uma autoridade.

[...] De outro turno, se a clareza corresponde ao uso semântico adequado das palavras a fim de evitar vagueza, ambigüidade ou obscuridade na mensagem, ela não poderá ser estudada sem que esteja correlacionada com o atributo precisão. (COAN, 2009: 4). 


\section{SEMINÁRIO DE PESQUISA EM CIÊNCIAS HUMANAS - SEPECH \\ Humanidades, Estado e desafios didático-científicos \\ Londrina, 27 a 29 de julho de 2016}

O que se condena é o excesso de formalismo, de rebuscamento, a falta de discernimento/sensibilidade na escolha/seleção lexical. Um grande exemplo disso foi o julgamento dos mensaleiros em 2012, em que os ministros do Supremo Tribunal Federal fizeram questão de falar difícil, em um julgamento que foi transmitido ao vivo para milhões de brasileiros. O Supremo Tribunal Federal, órgão máximo da Justiça da União no Brasil, e que tem como competência primordial a defesa da Constituição Federal, não deu tanta importância ao artigo 13 da Constituição em vigor que determina que "a Língua Portuguesa é o idioma oficial da República Federativa do Brasil", utilizando uma linguagem incompreensível para a maioria dos espectadores.

Guzzo (2012) comenta sobre o episódio em um tom sarcástico:

"Daria na mesma, no fundo, se os ministros do STF tivessem falado em javanês - tanto que foi indispensável, para os meios de comunicação, armar um serviço de tradução simultânea para as pessoas". Ainda salientou que:

O português tem cerca de 200000 palavras - mais do que o suficiente, portanto, para Suas Excelências encontrarem termos de compreensão mais fácil. Decidiram fazer justo o contrário: não perderam uma única oportunidade de substituir toda e qualquer palavra clara por outra que ninguém entende. Para que isso? Uma sentença não fica mais justa porque é escrita nessa linguagem torturada. É óbvio que num congresso de física molecular, cirurgia neurológica ou prospecção de petróleo os participantes têm de usar termos técnicos em sua conversa; são até obrigados a isso, para trabalhar com eficiência. Juristas podem fazer exatamente o mesmo, nos seus encontros profissionais. Mas magistrados exercem uma função pública - e isso exige que falem para o público, e não apenas para si mesmos.

\section{2. “JURIDIQUÊS” E A MOROSIDADE DA JUSTIÇA}

O "juridiquês " " também é para alguns pensadores um dos responsáveis pela lentidão da justiça brasileira. Peças processuais contendo mais de 100 páginas, contendo citações desnecessárias que engrossam os autos processuais.

Para Maciel (2007: 1):

Há transcrição exagerada de textos de leis, doutrinas e jurisprudências. Desconsidera o advogado, que um par de teses favoráveis ao seu pedido já é suficiente. O juiz nunca lerá integralmente uma petição extensa. Para conseguir despachar inúmeros processos diariamente, é obrigado a

\footnotetext{
${ }^{1}$ Juridiquês - uso desnecessário e excessivo de termos técnicos de Direito; vocábulo usado no Brasil que ainda não consta dos dois principais dicionários brasileiros (Aurélio Buarque de Holanda e Antonio Houaiss); trata-se, portanto, de um neologismo. Disponível em:

$<$ http://nossalinguaportuguesa.com.br/dicionario/juridiqu\%25EAs/>. Acesso em: 6 nov. 2013.
} 


\section{SEMINÁRIO DE PESQUISA EM CIÊNCIAS HUMANAS - SEPECH \\ Humanidades, Estado e desafios didático-científicos \\ Londrina, 27 a 29 de julho de 2016}

dispensar o supérfluo e se ater apenas ao essencial. Ao exagerar em citações, o peticionário estará somente desperdiçando tempo e engrossando os autos processuais. A economia textual é palavra de ordem na órbita da justiça e elemento mor para a celeridade dos processos. Ater-se ao formalmente necessário é meia causa ganha pelo profissional do direito.

Sabe-se também do caso de uma petição inicial que continha cento e vinte páginas. Mesmo esta estando bem encadernada, foi devolvida pelo juiz com um pedido de que fosse mais sucinta. Refeita a petição, ficou esta com 70 páginas. Como se tratava de uma simples reclamação trabalhista, o juiz novamente devolveu o pedido, exigindo mais objetividade. Por fim, o advogado entregou a petição contendo catorze páginas. Casos como esse demonstram o exagero na linguagem, que consome ainda mais o tempo das cortes superiores, que por sinal já estão sobrecarregadas com milhões de processos a serem resolvidos.

Frente a isso, Vianna (2008: 1) faz a seguinte menção:

Assim, salvo melhor juízo, as peças processuais devem primar pela simplicidade, concisão, clareza e objetividade. Os períodos devem ser curtos e na ordem direta, evitando-se adjetivações que pouco contribuem para esclarecimentos dos fatos e das teses. Com isso, facilita-se a transmissão das idéias - finalidade da palavra, escrita ou falada -, além de se correr menor risco de erros gramaticais. A propósito, vale lembrar Carlos Drummond de Andrade: "escrever bem é a arte de cortar palavras". E, ainda, Hegel: "quem exagera no argumento, prejudica a causa".

\section{LINGUAGEM FORENSE}

Para Nascimento (1992: 3):

A linguagem socializa e racionaliza o pensamento. É axiomático, modernamente, que quem pensa bem escreve ou fala bem. Assim cabe ao advogado e ao juiz estudar os processos do pensamento, que são objeto da Lógica, conjuntamente com a expressão material do pensamento que é a linguagem. Talvez nenhuma arte liberal necessite mais de forma verbal adequada que a advocacia [...]

Para uma linguagem ser considerada eficiente é imprescindível que apresente quatro qualidades essenciais: precisão, concisão, pureza e clareza.

Segundo Nascimento (1992), essas qualidades se definem da seguinte maneira:

a) PRECISÃO: se adquire por meio do estudo do sentido das palavras (semântica), de sua colocação e da organização das orações no período.

b) CONCISÃO: é a qualidade principal da linguagem forense, uma vez respeitadas as demais. Consiste na busca para a forma breve, incisiva para o 


\title{
XI SEMINÁRIO DE PESQUISA EM CIÊNCIAS HUMANAS - SEPECH \\ Humanidades, Estado e desafios didático-científicos \\ Londrina, 27 a 29 de julho de 2016
}

\begin{abstract}
A palavra "prescrição", por exemplo, não pode ser substituída por outra e seu uso afasta o cidadão do conteúdo do julgamento. Dessa forma, é necessário que se crie um mecanismo eficaz para explicar ao cidadão, sem formação jurídica, o que, efetivamente, foi decidido.

Da mesma forma que o médico não se restringe a dizer o nome da doença, mas busca explicar ao paciente o diagnóstico apresentado, o juiz não deve apenas julgar, mas precisa fazer com que o cidadão entenda o que foi decidido e as razões que o levaram a decidir daquela forma.
\end{abstract}

Ela também propõe que o Tribunal faça um texto explicativo e o divulgue pela internet, referente ao que foi determinado na Súmula. Por exemplo: a Súmula 278 do STJ estabelece que: "o termo inicial do prazo prescricional, na ação de indenização, é a data em que o segurado teve ciência inequívoca da incapacidade laboral".

Traduzindo isto significa que:

"A pessoa, que tiver contratado um seguro de vida e de acidentes pessoais e sofrer um acidente que a torne incapaz para o trabalho, terá um prazo máximo para pedir na justiça o pagamento de indenização. A Súmula 278 do STJ estabelece que esse prazo começa a ser contado a partir do dia em que a pessoa tiver a certeza de que não poderá mais trabalhar". Andrighi (2005).

\section{REFLEXÕES ACERCA DA MINHA PRÁTICA PEDAGÓGICA NA DISCIPLINA DIREITO E LINGUAGEM NO CURSO DE DIREITO DA CATÓLICA DE SANTA CATARINA EM JARAGUÁ DO SUL}

As reflexões sobre a questão da Simplificação da Linguagem Jurídica que discuto neste texto são fruto da minha vivência como professora da disciplina Direito e Linguagem, a qual ministro no curso de Direito do Centro Universitário Católica de Santa Catarina em Jaraguá do Sul. Tais reflexões não têm a intenção de dar conta da complexidade da linguagem, mas trazer para a sala de aula, principalmente a acadêmicos de Direito de fases iniciais, uma possibilidade de discussão/reflexão acerca da importância da linguagem usada nas mais diversas esferas, especialmente a jurídica.

Desde 2003 atuo como docente no curso de Direito do Centro Universitário Católica de Santa Catarina em Jaraguá do Sul. Na época ministrava a disciplina Linguagem Jurídica, a qual passou, em 2005, após longas reflexões sobre sua terminologia, a se chamar Direito e Linguagem. À época, os conteúdos trabalhados eram Argumentação Jurídica e Semiótica. Mas, em 2005, ao tomar conhecimento da campanha lançada pela AMB (Associação dos Magistrados Brasileiros) sobre a Simplificação da Linguagem Jurídica, resolvi levar esse importante assunto para a sala de aula, a fim de discutir com os acadêmicos sobre a importância da linguagem, especialmente na esfera jurídica, haja vista que o direito é uma ciência essencialmente linguística ou, melhor dizendo, é a mais linguística de todas as instituições. Como já dito aqui, AMB lançou, em 11 de agosto de 2005, na Escola de Direito da Fundação Getúlio Vargas, no Rio de Janeiro, uma campanha pela "Simplificação da Linguagem Jurídica" utilizada por magistrados, advogados, promotores e outros operadores da área, com o objeto de aproximar o Poder Judiciário do cidadão comum, através de uma 


\section{SEMINÁRIO DE PESQUISA EM CIÊNCIAS HUMANAS - SEPECH \\ Humanidades, Estado e desafios didático-científicos \\ Londrina, 27 a 29 de julho de 2016}

reeducação linguística nos tribunais e nas faculdades de Direito, com o uso de uma linguagem mais clara e objetiva. Partindo do mote: ninguém valoriza o que não conhece, a campanha teve por como foco os estudantes de Direito. Por meio de palestras do presidente da entidade, juiz Rodrigo Collaço, a AMB divulgou a iniciativa em quatro Estados: Rio de Janeiro, São Paulo, Minas Gerais, Paraná e no Distrito Federal. Também foi lançado um livreto com termos acessíveis, que transmitem as mesmas ideias das expressões complicadas frequentemente utilizadas nos documentos produzidos pelos profissionais do Direito. Para incentivar os estudantes a tomar consciência sobre a importância do uso de um vocabulário mais simples, a AMB criou um concurso para premiar os melhores trabalhos dos alunos de Direito relacionados à simplificação da linguagem jurídica. Outro concurso prestigiou os magistrados associados à entidade que desenvolvem no dia a dia formas de simplificar a linguagem utilizada em peças processuais, como sentenças e notificações, entre outras. Dentre os estudantes, os textos premiados foram: A Ponte (Claudia Dantas Ferreira da Silva UnB - DF); Com Complexidade não há igualdade (Pedro Carvalhaes Vieira UFMG); Linguagem Jurídica versus Comunicação (João Zacharias de Sá - FGV - Rio de Janeiro). Dentre os magistrados, os textos premiados foram: Embargos de Declaração (Rafael Infante Faleiros - Juiz de Franca (SP); A Clareza da Linguagem Judicial como Efetivação do Acesso à Justiça (Lourival de Jesus Serejo Sousa - Juiz de São Luís Maranhão); Pela Compreensão da Justiça (Fátima Nancy Andrighi - Ministra do Superior Tribunal de Justiça - Brasília - DF).

Então, em outubro de 2006, tive o privilégio de convidar e contar com a ilustre presença do Dr. Rodrigo Collaço em nosso Centro Universitário, o qual fez uma palestra para meus alunos sobre o referido tema. Desde então, todo semestre, possibilito aos meus alunos a leitura dos textos acima referidos e, a partir deles e de outras considerações que julgo pertinentes frente ao tema, peço-lhes que produzam um texto argumentativo posicionando-se acerca do tema em tela. Essa é uma forma que encontrei de levar à universidade, na figura dos alunos da $2^{\circ}$ fase de Direito, uma reflexão e, acima de tudo, um despertar para uma consciência linguística crítica, pois, como bem salientou Bacon, o grande ideal é "pensar como pensam os sábios, mas falar como falam as pessoas comuns". Também são bem-vindas as palavras do poeta Thiago de Mello: "falar difícil é fácil. O difícil é falar fácil".

\section{CONSIDERAÇÕES FINAIS}

Há uma enorme disparidade na comunicação do "Mundo Jurídico" com "Mundo Popular" que torna o Judiciário cada vez mais distante da sociedade. Há excessos (e exageros) na linguagem jurídica, na comunicação dos advogados e magistrados, nas peças processuais, nas súmulas, que vão além do técnico, do lógico, do racional, do eficiente, ou seja, que atinge o nível do 'blá-blá-blá', do supérfluo, do obscuro, do ridículo, que faz nascer "a morosidade mórbida do Judiciário de todos os dias".

Para sanar isso, é necessário clareza na comunicação, sensibilidade para saber com quem está lidando, ou seja, ser culto para com os cultos e simples para com os simples. Ter ciência de que a Justiça é para todos, sem exceção. É saber que um juiz, um promotor, um advogado, um operador do direito exerce seu ofício para promover justiça aos povos - "todo poder emana do povo" - e que este povo é composto por 


\title{
XI SEMINÁRIO DE PESQUISA EM CIÊNCIAS HUMANAS - SEPECH \\ Humanidades, Estado e desafios didático-científicos \\ Londrina, 27 a 29 de julho de 2016
}

pessoas de diferentes classes sociais, intelectuais, culturais e econômicas, e que também possuem o direito de entender seus direitos.

Em síntese, simplificar a linguagem jurídica não é sinônimo de involução intelectual, o contrário disso, é evolução! Já dizia Machado de Assis (apud FETZNER, 2006: 5):

\begin{abstract}
Não há dúvida de que as línguas se aumentam e alteram com o tempo e a necessidade dos usos e costumes. Querer que a nossa pare no século de quinhentos, é um erro igual ao de afirmar que sua transplantação para a América Latina não lhe inseriu riquezas novas. A este respeito a influência do povo é decisiva. $[\ldots]$
\end{abstract}

A simplicidade é maior do que a complexidade; simplicidade está no nível da nobreza, da realeza. $\mathrm{O}$ operador de direito que compreende isso deixa de ser um mero "doutor da lei", um profissional fabricado em laboratório e terá mais condições de promover o bem-estar de toda coletividade, concedendo e garantindo os direitos fundamentais essenciais ao desenvolvimento humano, aliado à democracia, que afirma a soberania popular no poder como instrumento de efetivação dos direitos previstos, ocupando o judiciário um importante papel de interpretar e aplicar os direitos fundamentais previstos na Constituição.

Por fim, segue uma citação de Sócrates para complementar o raciocínio: "Devese organizar o discurso de tal maneira que os discursos simples sejam dirigidos às almas simples e os discursos mais complexos e abrangentes às almas mais elevadas".

\section{REFERÊNCIAS}

ANDRIGHI, Fátima Nancy. Pela compreensão da Justiça. AMB. 2005. < disponível em: http://www.amb.com.br/?secao=campanha_juridiques $>$. Acesso em: 18 nov. 2013.

BAIÃO, Rosaura de Barros. A fala do Advogado. Rio de Janeiro. CAMPANHA Pela Simplificação da Linguagem Jurídica. AMB. 2005. <disponível em: http://www.amb.com.br/?secao=campanha_juridiques>. Acesso em: 14 nov. 2013.

CHALITA, Gabriel. A sedução no discurso: o poder da linguagem nos tribunais de júri. 4 ed. São Paulo: Saraiva, 2007.

COAN, Emerson Ike. Atributos da linguagem jurídica. Teresina, Jus Navigandi, 8 mar. 2009. Disponível em: < http://jus.com.br/artigos/12364/atributos-da-linguagemjuridica/print $>$. Acesso em: 01 nov. 2013.

FETZNER, Néli Luiza Cavalieri et al (Coord.). Argumentação Jurídica: teoria e prática. Rio de Janeiro: Freitas Bastos, 2006. 


\section{SEMINÁRIO DE PESQUISA EM CIÊNCIAS HUMANAS - SEPECH \\ Humanidades, Estado e desafios didático-científicos \\ Londrina, 27 a 29 de julho de 2016}

GUZZO, José Roberto. 'Tudo em javanês'. São Paulo: Veja, 18/11/2012. Disponível em: $\quad<$ http://veja.abril.com.br/blog/augusto-nunes/feira-livre/tudo-em-javanes-por-j-rguzzo/>. Acesso em 23 out. 2013

MACIEL, Roger Luiz. Linguagem jurídica: é difícil escrever direito?. Teresina: Jus Navegandi, 19 jul. 2007. Disponível em:< http://jus.com.br/artigos/10169/linguagem-juridica/print>. Acesso em 23 out. 2013.

NASCIMENTO, Edmundo Dantès. Linguagem Forense: a língua portuguesa aplicada à linguagem do foro. 10 ed. São Paulo: Saraiva, 1992.

VIANNA, José Ricardo Álvares. Simplificação da linguagem jurídica. Teresina. Jus Navegandi, 4 maio 2008. Disponível em: $<$ http://jus.com.br/artigos/11230/simplificacao-da-linguagem-juridica/print $>$. Acesso em 6 nov. 2013. 